\title{
Viajeros a Asia
}

Pontificia Universidad Católica de Chile.

Departamento de Medicina Interna.

Recibido: 10 de enero de 2011

Correspondencia a: Elvira Balcells $\mathrm{M}$. balcells@med.puc.cl
A sia es el continente más extenso y más poblado del planeta, e incluye una gran diversidad de países que son tremendamente interesantes para el mundo occidental por su bagaje histórico, diversidad cultural, gastronómica y geográfica. Sin embargo, en ciertos países de este continente el viajero se verá en riesgo de adquirir infecciones que pueden no existir en su país de origen y que son fácilmente transmitidas por los alimentos, contactos con ciertos animales o insectos, si no se toman medidas preventivas. El riesgo varía según la edad y co-morbilidades del viajero, tipo y duración del viaje; por lo tanto, las recomendaciones de prevención van a diferir según la situación individual.

\section{Asia del Este}

La región de Asia del Este o Asia Oriental incluye China, Hong Kong, Japón, Mongolia, Corea del Norte, Corea del Sur y Taiwán. Abarca población sinoparlante, japonesa, coreana y mongola. Algunos de estos países tienen pocos riesgos de salud para el viajero por ser muy desarrollados y formar parte del $25 \%$ superior de la economía mundial, tales como Japón, Corea del Sur y Hong Kong; otros en cambio, son países en desarrollo, con condiciones de vida y estándares de salud más precarios, como Corea del Norte y Mongolia.

Información complementaria y más detallada sobre los riesgos de salud en países de Asia del Este puede ser encontrada en: http://wwwnc.cdc.gov/travel/regions/ east-asia.aspx

\section{Enfermedades prevenibles por vacunas en Asia del Este}

Los viajeros a Asia del Este deben actualizar sus vacunas contra difteria/tétanos, sarampión e influenza. La vacuna contra la hepatitis A se recomienda a todos los viajeros y la vacuna de hepatitis B sólo para viajes prolongados o para aquellos viajeros que pudiesen exponerse a fluidos corporales, sangre, contacto sexual o eventuales tratamientos médicos locales de urgencia.

La vacuna contra la fiebre tifoidea se recomienda a todos los viajeros que van a Mongolia y Corea del Norte, y a China si visitan pequeños pueblos o áreas rurales donde pudiesen exponerse a través de la comida o el agua. Para el resto de países de esta región esta es una vacuna opcional.

No es necesario el refuerzo de vacuna de polio para los países de esta región, a excepción de aquellos que se dirijan a la Región Autónoma de Xinjiang Uyghur, en China.

La vacuna del virus de la encefalitis japonesa está indicada para viajes a Taiwán, Japón y China, en particular si se tienen planificadas estadías prolongadas en zonas rurales o estadías más cortas pero frecuentes en las zonas de riesgo de estos tres países. En Corea del Sur, Corea del Norte y Hong Kong el riesgo de encefalitis japonesa es más esporádico y sólo limitado a ciertas áreas rurales. Para ver detalles de las zonas endémicas consulte: wwwnc.cdc.gov/travel/yellowbook/2010/chapter-2/ japanese-encephalitis. Esta vacuna no está actualmente disponible en Chile.

La vacuna anti-rábica pre-exposición está recomendada para los países de Asia del Este en aquellos viajeros que prevean pasar mucho tiempo en exteriores, particularmente en áreas rurales, en actividades como ciclismo, camping o trekking. También es recomendable para viajeros con significativo riesgo ocupacional (como veterinarios), viajes muy prolongados o viajes con niños pequeños, que se consideran con mayor riesgo de sufrir mordeduras de animales.

No es necesario vacunarse contra la fiebre amarilla para viajar a estos países de Asia del Este ya que no existe riesgo de transmisión de esta enfermedad. Sin embargo, si el viajero proviene o se ha detenido en un país donde sí existe fiebre amarilla, se le puede exigir mostrar evidencia de inmunización para entrar a China y Corea del Norte. La lista de países con riesgo de transmisión de fiebre amarilla se encuentra disponible en http://wwwnc.cdc. gov/travel/yellowbook/2010/chapter-2/yellow-fevervaccine-requirements-and-recommendations.aspx

\section{Malaria en Asia del Este}

Existe malaria, exclusivamente por Plasmodium vivax, en ciertas regiones de China, variadas zonas de Corea del Norte y de Corea del Sur. En China, la malaria se da en partes rurales de las provincias de Anhui, Guizhou, Henan, Hubei, Hainan, y Yunnan. No hay malaria en grandes ciudades y áreas urbanas. Sin embargo, algunos cruzeros de ríos pueden atravesar áreas endémicas en las 
provincias de Anhui y Hubei. Más detalles y mapas de malaria están disponibles en http://www.cdc.gov/malaria/ map/index.html

Para prevenir la malaria, es necesario evitar las picaduras de mosquitos además de tomar el antimalárico profiláctico que esté indicado. Es recomendable usar ropa de colores claros, manga larga y pantalones largos, evitar perfumes y utilizar repelente adecuado (DEET $>20 \%$ o bien picaridina). En las habitaciones se puede usar spray insecticida (que contenga piretroides) y se recomienda uso de mosquiteros pre-tratados con permetrina o deltametrina para la cama, a menos que se duerma en habitación con aire acondicionado o ventanas selladas. El antimalárico efectivo en prevención es la cloroquina, tanto en Corea del Sur, Corea del Norte como todas las áreas de China, a la excepción de Hainan y Yunnan donde existe resistencia a cloroquina y se requiere usar atovacuona/proguanil $\left(\right.$ Malarone $^{\mathbb{R}}$ ) o doxiciclina.

\section{Otras enfermedades transmitidas por insectos en Asia del Este}

Además de la malaria, en algunas zonas geográficas existe riesgo de infección por virus de encefalitis japonesa. (Ver recomendaciones de vacunas en sección "Enfermedades prevenibles por vacunas").

El dengue es prevalente en casi toda Asia y brotes de dengue han sido descritos ocasionalmente en ciertas provincias de China, Hong Kong y recientemente, con incidencia el doble de lo habitual, en el Sur de Taiwan. Otro virus transmitido por mosquitos es el Chikungunya (familia Arbovirus) y brotes de infección aguda han sido descritos también en las provincias de Donguan y Guangdong en China. El uso correcto de repelente es la única manera efectiva de prevenirlos.

Otras infecciones transmitidas por insectos, que pudieran ocasionalmente afectar a viajeros en estos países, son la filiariasis, leishmaniasis y la plaga. La protección contra insectos ayuda a prevenirlas. La encefalitis asociada a garrapatas ocurre en las regiones boscosas del noreste de China (borde con Rusia), en áreas de Japón y de Corea del Sur, existiendo una vacuna que actualmente no está disponible en Chile, la que podría indicarse a viajeros a esa zona.

\section{Otros riesgos y enfermedades presentes en Asia del Este}

Las infecciones respiratorias son frecuentes en viajeros a Asia. Entre ellas, probablemente la más grave sea la influenza aviar (A/H5N1) que ha causado brotes en aves domésticas y salvajes en varios países del este asiático. Se recomienda evitar todo contacto con aves, incluyendo las aves de corral, y evitar lugares como aviarios o mercados de aves. (Para obtener mayor información sobre fechas y lugares de brotes de influenza A/H5N1 ver http://www. who.int/csr/disease/avian_influenza/en/)

El riesgo de adquirir infecciones intestinales es alto en toda la región de Asia del Este, a excepción de Japón y de hoteles de lujo en China y Hong Kong. Las medidas preventivas para el resto de las áreas son, fundamentalmente, consumir agua o bebidas envasadas (no de la llave, salvo que esté hervida por 1 minuto o bien purificada con tabletas de cloro o filtros portátiles), preferir los alimentos recién cocidos y la fruta o verduras crudas solamente si han sido lavadas y luego peladas. Es importante evitar el comer mariscos o pescados crudos por riesgo de infecciones por trematodes. Es recomendable llevar loperamida y una quinolona para el tratamiento empírico en caso de diarrea.

No es recomendable nadar en agua dulce (ríos, estanques y lagos), salvo piscinas bien clorinadas, en ciertas regiones de China por el riesgo de adquirir esquistosomiasis (larvas Schistosoma japonicum que penetran la piel al bañarse). Esta está presente en áreas focales a lo largo del valle del río Yangtze, lago Dongting y lago Poyang.

Enfermedad por hantavirus ha sido descrita en regiones de China, Mongolia, Corea del Norte y Corea del Sur. Se recomienda evitar el contacto con roedores en esas zonas.

Por último, es fundamental educar y recomendar sobre el riesgo de rabia, que es alto en China (no en Hong Kong) y en Mongolia. La vacuna antirábica pre-exposición es recomendable para todos los viajeros a Mongolia y para los viajes prolongados a China, con prioridad para los niños. En cualquiera de estos países la conducta recomendada ante cualquier mordedura o rasguño causada por perros, gatos, monos, animal salvaje carnívoro, o contacto con murciélagos, es primero lavarse de inmediato en forma profusa con agua y jabón la zona afectada durante al menos 15 minutos, y luego concurrir al centro médico más grande cercano para ponerse las vacunas anti-rábicas.

Finalmente, es importante prevenir el mal de alturas si se planifica viajar a zonas sobre los 2.400 metros, tal como Lhasa (Tibet) (3.700 metros), y la mayor parte de Qunghai, Xinjiang, Sichuan, Yannan y Gansu en China. Se recomienda uso de acetazolamida en forma preventiva.

\section{Asia del Sur}

Asia del Sur o Meridional es la sub-región de Asia que abarca los países comprendidos entre Irán y la India, aunque Irán generalmente se categoriza como parte del Medio Oriente. Desde el punto de vista geográfico, se trata de la suma de la meseta iraní (al sur del mar Caspio y Asia Central) y del sub-continente índico (al sur de los Himalayas). Se dividen entre países musulmanes y países de religiones dhármicas.

La región agrupa los siguientes países: Afganistán, 
Bangladesh, Bután, India, Maldivas, Nepal, Pakistány Sri Lanka. Algunos de estos son destinos turísticos frecuentes, particularmente India y Nepal, por su interés histórico y cultural. En los últimos años han ocurrido enfrentamientos que han desestabilizado países de la región, tal como la guerra de Afganistán, el conflicto de Cachemira y la Guerra Civil de Sri Lanka. Mayor información sobre los riesgos de salud en estos destinos se puede encontrar en: http://wwwnc.cdc.gov/travel/regions/south-asia.aspx

\section{Enfermedades prevenibles por vacunas en Asia del Sur}

Todos los viajeros deben actualizar sus vacunas contra difteria/tétanos, sarampión e influenza. Se recomienda a todos los viajeros la vacuna contra hepatitis A. La vacuna de hepatitis B se recomienda para todos los viajeros a Afganistán y para el resto de los países de este grupo, sólo en caso de estadías prolongadas, potencial exposición a fluidos corporales, sangre, se prevea contacto sexual o tratamiento médico local de urgencia.

La vacuna contra la fiebre tifoidea está recomendada para todos los viajeros a estos países de Asia del Sur. La vacuna de la polio inactivada (IPV) debe ser actualizada antes de viajar a Afganistán, Bangladesh, Bhutan, India, Nepal y Pakistán. No es necesaria para las Maldivas o Sri Lanka.

La vacuna del virus de la encefalitis japonesa está indicada para viajes a Bangladesh, India (a excepción de Himachal, Pradesh, Jammu \& Kashmir y Rajasthan), Nepal (para Terai y valle de Kathmandu), Sri Lanka, Buthan y Pakistán (escasos datos disponibles para estos últimos dos), en particular para estadías prolongadas en zonas rurales por o estadías más cortas pero frecuentes en las zonas de riesgo. (Para ver detalles de zonas de mayor riesgo consulte: wwwnc.cdc.gov/travel/yellowbook/2010/ chapter-2/japanese-encephalitis). Esta vacuna no está actualmente disponible en Chile.

La vacuna anti-rábica es recomendable para todos los viajeros a Afganistán por ser considerado país de alto riesgo. En todo el resto de los países de esta zona es una vacuna a considerar de manera opcional -particularmente para viajes a India y Nepal- en aquellos viajeros que prevean pasar mucho tiempo en exteriores, particularmente en áreas rurales, en actividades como ciclismo, camping o trekking. También es recomendable para viajeros con significativo riesgo ocupacional (como veterinarios) y para viajes muy prolongados, con prioridad a niños pequeños ya que se consideran con mayor riesgo de sufrir mordeduras de animales.

No es necesario vacunarse contra la fiebre amarilla para viajar a estos países de Asia del Sur ya que no existe riesgo de transmisión de esta enfermedad. Sin embargo, si el viajero proviene o hizo escala en un país en que sí existe fiebre amarilla, se le puede exigir mostrar evidencia de inmunización para entrar a cualquiera de estos países. La lista de países con riesgo de fiebre amarilla se encuentra disponible en http://wwwnc.cdc.gov/travel/yellowbook/2010/chapter-2/yellow-fever-vaccine-requirementsand-recommendations.aspx La lista oficial de India difiere de la lista de la OMS, al incluir Zambia y omitir Argentina, Mauritania y Paraguay.

Por último, la vacuna contra el cólera está actualmente recomendada sólo en situaciones de brote o para personas que van a trabajar a campos de refugiados en Afganistán, Bangladesh, India y Pakistán.

\section{Malaria en Asia del Sur}

Existe riesgo de malaria en todos los países de Asia del Sur a excepción de Maldivas. La malaria es, en general, producida tanto por Plasmodium falciparum como $P$. vivax, y el riesgo varía según la ruralidad y la altura; por lo tanto, es fundamental revisar el mapa actualizado de zonas maláricas en cada destino para evaluar la magnitud del riesgo y las medidas preventivas. A modo de ejemplo, en India la transmisión de malaria ocurre a lo largo de todo el año, pero el riesgo aumenta significativamente en la época del monzón (junio a septiembre). Algunas áreas requieren uso de antimalárico preventivo pero, en general las grandes urbes como Agra, Nueva Delhi o Calcuta, son de mucho menor riesgo y basta sólo con el repelente. Más detalles y mapas de malaria están disponibles en http:// www.cdc.gov/malaria/map/index.html

Para prevenir la malaria en estos países es importante prevenir las picaduras de insectos además de tomar antimalárico profiláctico cuando esté indicado. Para prevenir picaduras de mosquitos se recomienda usar ropa de colores claros, manga larga y pantalones largos, evitar perfumes y utilizar repelente adecuado (DEET $>20 \%$ o bien picaridina). En las habitaciones se puede usar spray insecticida (que contenga piretroides) y se recomienda uso de mosquiteros pre-tratados con permetrina o deltametrina para la cama en zonas de malaria, a menos que se duerma en habitación con aire acondicionado o ventanas selladas. Antimaláricos de utilidad en esta región son la atovacuona/proguanil (Malarone ${ }^{\mathbb{B}}$ ), mefloquina $\left(\operatorname{Lariam}^{\mathbb{R}}\right)$ y doxiciclina. Existe resistencia a cloroquina y no debe por tanto utilizarse en viajeros a esta zona.

\section{Otras enfermedades transmitidas por insectos en Asia del Sur}

Además de la malaria, en algunas zonas geográficas existe riesgo de infección por virus de encefalitis japonesa. (Ver recomendaciones de vacunas en sección "Enfermedades prevenibles por vacunas").

La infección por virus dengue es prevalente en Bangladesh, Bhutan, India (frecuentes brotes), islas Maldivas, Pakistán, Nepal y Sri Lanka. Brotes de infección aguda 
por virus Chikungunya (familia Arbovirus, transmitido por mosquitos) ocurren en la parte sur de India, particularmente en Karnataka y Kerala, al igual que en las islas Maldivas y Sri Lanka. Para ambos se recomienda observar medidas de prevención diurna y nocturna contra picaduras de insectos.

Actividad esporádica de la fiebre hemorrágica de Crimea-Congo ocurre en Afganistán y en Pakistán (Balochistan). Es recomendable tomar precauciones contra garrapatas y evitar todo contacto directo con sangre o tejido de ganado en estas zonas.

Por último, en la mayoría de estos países de Asia del Sur existe riesgo de leishmaniasis, infección transmitida por insectos, la cual sólo es prevenible con el uso de un repelente adecuado.

\section{Otros riesgos y enfermedades presentes en Asia del Sur}

Las infecciones respiratorias son frecuentes en viajeros a Asia. Entre ellas, probablemente la más grave sea la influenza aviar (A/H5N1) que ha causado brotes en aves domésticas y salvajes en varios países del sur asiático. Se recomienda evitar todo contacto con aves, incluyendo las aves de corral, y evitar lugares como aviarios o mercados de aves (Para obtener mayor información sobre brotes de influenza H5N1 ver http://www.who.int/csr/disease/ avian_influenza/en/).

El riesgo de adquirir infecciones intestinales es alto en todos los países de esta región. Las medidas preventivas para el resto de las áreas son fundamentalmente consumir agua o bebidas envasadas (no de la llave, salvo que esté hervida por 1 minuto o bien purificada con tabletas de cloro o filtros portátiles), preferir los alimentos recién cocidos y la fruta o verduras crudas solamente si son lavados y luego pelados. Es recomendable llevar loperamida y una quinolona para tratamiento empírico en caso de diarrea. En India, el antimicrobiano recomendado en caso de diarrea del viajero es azitromicina (alta tasa de resistencia a quinolonas).

Recientemente (septiembre de 2010) han sido descritos más de 600 casos de antráx (cutáneo) en Bangladesh (Sirajganj) debido a contacto directo con carnes contaminadas; el riesgo a viajeros es mínimo pero se recomienda evitar contacto con ganado y consumo de carnes de vacuno en esta zona.

En cualquiera de estos países la conducta recomendada ante cualquier mordedura o rasguño causada por perros, gatos, monos, animal salvaje carnívoro, o contacto con murciélagos, es: primero lavarse de inmediato en forma profusa con agua y jabón la zona afectada, durante al menos 15 minutos, y luego concurrir al centro médico más grande cercano para ponerse las vacunas anti-rábicas. Las mordeduras por monos son frecuentes en turistas en la India y Nepal, pudiendo transmitir además de rabia in- fección por virus herpes B. Para prevenirlas es importante evitar alimentar a los monos.

Por último, es importante prevenir el mal de alturas si se planifica viajar a zonas sobre los 2.400 metros, en Nepal (Kathmandu y Pokhara) y Buthan. Se recomienda uso de acetazolamida en forma preventiva.

\section{Sudeste Asiático}

El Sudeste Asiático es la sub-región de Asia situada al sur de China y al este de la India. Suele considerarse parte de Extremo Oriente e incluye países que tienen entre sí cierta unidad cultural e histórica. Estos son: Brunei, Burma (Myanmar), Cambodia, Indonesia, Laos, Malasia, Filipinas, Singapur, Tailandia, Timor-Leste (Timor del Este) y Vietnam. Son destino turístico muy apetecido, y generalmente los viajes programan paso por varios de los países en forma consecutiva. Información más detallada sobre los riesgos de salud en estos destinos puede ser encontrada en: http://wwwnc.cdc.gov/travel/regions/ southeast-asia.aspx

\section{Enfermedades prevenibles por vacunas en el Sudeste Asiático}

Todos los viajeros deben actualizar sus vacunas contra difteria/tétanos, sarampión e influenza. Se recomienda además a todos los viajeros la vacuna contra hepatitis A y la fiebre tifoidea, a excepción de viajes a Brunei Darussalam y Singapur, donde el riesgo de adquirir estas infecciones es muy bajo. La vacuna de hepatitis B se recomienda sólo para aquellos viajeros con estadías prolongadas o que pudiesen exponerse a fluidos corporales o sangre, prevén contacto sexual o tratamiento médico local de urgencia para el resto de los países de este grupo.

El único país de este grupo para el cual es recomendable actualizar la vacuna de la polio (IPV en adultos) es Burma.

La vacuna del virus de la encefalitis japonesa está indicada para viajes a Cambodia, Timor-Leste, Brunei Darussalam, Burma, Indonesia, Laos, Malasia, Filipinas, Tailandia y Vietnam, en particular para estadías prolongadas en zonas rurales o estadías más cortas pero frecuentes en las zonas de riesgo. Para ver detalles de zonas de mayor riesgo: wwwnc.cdc.gov/travel/yellowbook/2010/ chapter-2/japanese-encephalitis. Esta vacuna no está actualmente disponible en Chile.

La vacuna anti-rábica es recomendable para los viajeros a Burma, Cambodia, Laos, Vietnam, Indonesia, Filipinas, Tailandia, Brunei Darussalam y Timor-Leste. Se recomienda vacunar a aquellos viajeros que prevean pasar mucho tiempo en exteriores, particularmente en áreas rurales, en actividades como ciclismo, camping 
o trekking. También es recomendable para viajeros con significativo riesgo ocupacional (como veterinarios) y para viajes muy prolongados, con prioridad a niños pequeños ya que se consideran con mayor riesgo de recibir mordeduras de animales. En Malasia y Singapur, el riesgo de rabia es mínimo y la vacuna sólo está recomendada para riesgo ocupacional o probabilidad de contacto con murciélagos.

La vacuna contra la fiebre amarilla no es necesaria para viajar al Sudeste Asiático ya que no existe riesgo de transmisión en estos países. Sin embargo, si el viajero proviene o hace previamente escala en un país en que sí existe fiebre amarilla, se le puede exigir mostrar evidencia de inmunización para entrar a cualquiera de estos países. La lista de países con riesgo de fiebre amarilla se encuentra disponible en http:/wwwnc.cdc.gov/travel/yellowbook/2010/chapter-2/yellow-fever-vaccine-requirementsand-recommendations.aspx

Por último, la vacuna contra el cólera está actualmente recomendada sólo en situaciones de brote o para personas que van a trabajar a campos de refugiados en Filipinas y Tailandia.

\section{Malaria en Sudeste Asiático}

Existe riesgo de malaria en todos los países del Sudeste Asiático, con excepción de Singapur y Brunei. Existe, en general, tanto malaria por P. falciparum como P. vivax, y el riesgo varía según la ruralidad y la altura; por lo tanto, es fundamental revisar el mapa actualizado de zonas maláricas en cada destino para evaluar la magnitud del riesgo y cuáles serían las medidas preventivas. Algunas áreas requieren uso de antimalárico profiláctico y otras de menor riesgo sólo repelente. Más detalles y mapas de malaria están disponibles en http://www.cdc.gov/malaria/ map/index.html

Para prevenir la malaria en estos países es importante evitar las picaduras de insectos, además de tomar el antimalárico profiláctico cuando esté indicado. Para minimizar las picaduras de mosquitos se recomienda usar ropa de colores claros, manga larga y pantalones largos, evitar perfumes y utilizar repelente adecuado (DEET $>20 \%$ o bien picaridina). En las habitaciones se puede usar spray de insecticida (que contenga piretroides) y se recomienda uso de mosquiteros pre-tratados con permetrina o deltametrina para la cama, a menos que se duerma en habitación con aire acondicionado o ventanas selladas. Antimaláricos de utilidad en estos países son atovacuona/proguanil y doxiciclina. Existe resistencia a cloroquina en toda esta región. Mefloquina es útil en ciertas áreas, pero en otras existe resistencia a ella como por ejemplo en algunos sectores de Myanmar, Tailandia, Laos, Cambodia y Vietnam, por lo que se sugiere ver detalles en http:/wwwnc.cdc.gov/travel/yellowbook/2010/ chapter-2/malaria-risk-information-and-prophylaxis.aspx

\section{Otras enfermedades transmitidas por insectos en Sudeste Asiático}

Además de la malaria, en algunas zonas geográficas existe riesgo de infección por virus de encefalitis japonesa. (Ver recomendaciones de vacunas en sección "Enfermedades prevenibles por vacunas").

La infección por virus dengue es muy prevalente en todos los países del Sudeste Asiático, con brotes frecuentes, tanto en zonas urbanas como rurales. El uso correcto de repelente es la única manera efectiva de prevenirlo. Brotes de infección aguda por virus Chikungunya (familia Arbovirus) transmitida por mosquitos, ocurren en las islas de Java y Sumatra (Indonesia), Malasia peninsular, en Singapur y Tailandia (principalmente la parte sur del país). Se recomienda la prevención diurna y nocturna de picaduras de insectos.

Infecciones por rickettsias, incluyendo tifus de los matorrales (Orientia tsutsugamushi) y tifus murino (Rickettsia typhi) ocurren en Cambodia, Laos, Tailandia y Viet Nam. Se recomienda protegerse de las garrapatas, ácaros y pulgas en zonas donde abundan roedores.

\section{Otros riesgos y enfermedades presentes en Sudeste Asiático}

En diversos países del Sudeste Asiático (Burma, Cambodia, Indonesia, Laos, Malasia, Tailandia y Vietnam) ha habido brotes de influenza aviar (A/H5N1) en aves domésticas y salvajes. Se recomienda evitar todo contacto con aves, incluyendo las aves de corral y evitar lugares como aviarios o mercados de aves. Para obtener mayor información sobre brotes de influenza A/H5N1 ver http:// www.who.int/csr/disease/avian_influenza/en/

El riesgo de diarrea del viajero es alto en todos los países de esta región, a excepción de Brunei y Singapur, donde la sanitización del agua es buena y los riesgos de adquirir infecciones entéricas por la bebida o los alimentos son mínimos. Las medidas preventivas para el resto de las áreas son, fundamentalmente, consumir agua o bebidas envasadas (no de la llave, salvo que esté hervida por 1 minuto o bien purificada con tabletas de cloro o filtros portátiles), preferir los alimentos recién cocidos y la fruta o verduras crudas solamente si son lavados y luego pelados. Es importante evitar el consumo de mariscos o pescados crudos, en particular en Laos, por el riesgo de adquirir infecciones por trematodes. Es recomendable llevar loperamida y una quinolona para tratamiento empírico en caso de diarrea. En Tailandia, el antimicrobiano recomendado en caso de diarrea del viajero es azitromicina (alta tasa de resistencia a quinolonas).

El riesgo de adquirir esquistosomiasis -larvas que penetran la piel al bañarse- existe en Cambodia, en las provincias de Stoeng Treng y Kracheh, a lo largo del río Mekong y sus tributarios; en Indonesia, en los valles de Napu y Lindu de la región central de la isla Sulawesi; en 
Laos, donde el riesgo es alto en la Provincia de Champassak a los alrededores del río Mekong (particularmente en isla Khong); en Filipinas, islas de Mindanao, Samar y Leyte, al igual que en la provincia de Sorsogon e isla Mindoro y Viet Nam (río Mekong y sus tributarias). Se recomienda evitar baños en agua dulce en esas zonas.

Por último, al igual que en las otras regiones de Asia, en cualquiera de estos países la conducta recomendada ante cualquier mordedura o rasguño causada por perros, gatos, monos, animal salvaje carnívoro, o contacto con murciélagos, es: primero lavarse de inmediato en forma profusa con agua y jabón la zona afectada, durante al menos 15 minutos, y luego concurrir al centro médico más grande cercano para ponerse las vacunas anti-rábicas. Las mordeduras por monos son frecuentes en turistas en Indonesia y Viet Nam, pudiendo transmitir además de rabia infección por virus herpes B. Es importante evitar la costumbre de alimentar a los monos. 